\title{
The Striatal Neurotensin Receptor Modulates Striatal and Pallidal Glutamate and GABA Release: Functional Evidence for a Pallidal Glutamate-GABA Interaction via the Pallidal-Subthalamic Nucleus Loop
}

\author{
Luca Ferraro, ${ }^{1}$ Tiziana Antonelli, ${ }^{1}$ William T. O’Connor, ${ }^{2}$ Kjell Fuxe, ${ }^{3}$ Philippe Soubrié, ${ }^{4}$ and Sergio Tanganelli ${ }^{1}$ \\ ${ }^{1}$ Department of Clinical and Experimental Medicine, Pharmacology Section, University of Ferrara, 44100 Ferrara, Italy, \\ 2Department of Human Anatomy and Physiology, University College of Dublin, Dublin, Ireland, ${ }^{3}$ Department of \\ Neuroscience, Karolinska Institute, Stockholm, Sweden, and ${ }^{4}$ Sanofi Recherche, 34184 Cedex 04, Montpellier, France
}

In the present study, we used dual-probe microdialysis to investigate the effects of intrastriatal perfusion with neurotensin (NT) on striatal and pallidal glutamate and GABA release. The role of the pallidal $\mathrm{GABA}_{\mathrm{A}}$ receptor in the intrastriatal NTinduced increase in pallidal glutamate release was also investigated.

Intrastriatal NT (100 and $300 \mathrm{~nm}$ ) increased striatal glutamate and GABA (100 nm, $155 \pm 9$ and $141 \pm 6 \%$, respectively; $300 \mathrm{~nm}, 179 \pm 8$ and $166 \pm 11 \%$, respectively) release, as well as pallidal glutamate and GABA (100 nM, $144 \pm 8$ and $130 \pm 5 \% ; 300 \mathrm{~nm}, 169 \pm 9$ and $157 \pm 8 \%$, respectively) release. These effects were dose-dependently antagonized by the NT receptor antagonist 2-[(1-(7-chloro-4-quinolinyl)5-(2,6-dimethoxy-phenyl)pyrazol-3-yl)carboxylamino]tricyclo) 3.3.1.1. ${ }^{3.7}$ )-decan-2-carboxylic acid (SR48692).

Intrasubthalamic injection of the $\mathrm{GABA}_{\mathrm{A}}$ receptor antagonist (-)-bicuculline (10 pmol/100 $\mathrm{nl}, 30 \mathrm{sec}$ ) rapidly increased pallidal glutamate release, whereas the intrastriatal NT-induced increase in pallidal glutamate release was counteracted by intrapallidal perfusion with (-)-bicuculline, suggesting that an increase in striopallidal GABA-mediated inhibition of the GABAergic pallidal-subthalamic pathway results in an increased glutamatergic drive in the subthalamic-pallidal pathway.

These results demonstrate a tonic pallidal GABA-mediated inhibition of excitatory subthalamic-pallidal neurons and strengthen the evidence for a functional role of NT in the regulation of glutamate and GABA transmission in the basal ganglia. The ability of intrastriatal SR48692 to counteract the NT-induced increase in both striatal and pallidal glutamate and GABA release suggests that blockade of the striatal NT receptor may represent a possible new therapeutic strategy in the treatment of those hypokinetic disorders implicated in disorders of the indirect pathway mediating motor inhibition.

Key words: basal ganglia; striatum; globus pallidus; neurotensin; SR48692; microdialysis; awake rat
The striatum regulates the activity of the GABAergic projection neurons of the substantia nigra pars reticulata $(\mathrm{SNr})$ via two main functional opposing pathways, the direct and indirect pathways (Albin et al., 1989; Alexander and Crutcher, 1990; Gerfen, 1992). The former is represented by the striatonigral GABAergic projection and monosynaptically inhibits the nigrothalamic GABA pathway, leading to a thalamic disinhibition of the glutamatergic drive to the cortex and therefore leading to movement initiation, whereas the latter encompasses a trisynaptic link including (1) a GABAergic projection from the striatum to the globus pallidus (GP), (2) a GABAergic projection from the GP to the subthalamic nucleus (STN), and (3) a glutamatergic projection from the STN to the SNr, which also innervates the GP. Activation of the striopallidal "link" in the indirect pathway is associated with an increase in STN glutamatergic input to the SNr and GP, and this results in changes in both thalamic activity and locomotor behavior opposite to those elicited by activation of the direct pathway

\footnotetext{
Received March 4, 1998; revised June 9, 1998; accepted June 11, 1998.

This work has been supported by Sanofi Recherche, Montpellier, France.

Correspondence should be addressed to Dr. S. Tanganelli, Department of Clinical and Experimental Medicine, Pharmacology Section, University of Ferrara, Via Fossato di Mortara 17-19, 44100 Ferrara, Italy.

Copyright (C) 1998 Society for Neuroscience $0270-6474 / 98 / 186977-13 \$ 05.00 / 0$
}

(Albin et al., 1989; Alexander and Crutcher, 1990; Chevalier and Deniau, 1990).

Neurotensin (NT) is a 13-amino acid peptide (Carraway and Leeman, 1973) that is widely distributed in the striatum (Jennes et al., 1982; Quirion et al., 1985; Deutch and Zahm, 1992; Fuxe et al., 1992a; Castel et al., 1994). The existence of a reciprocal modulation between neurotensinergic and dopaminergic systems in several brain areas has been demonstrated by many functional studies (Nemeroff and Cain, 1985; Blaha et al., 1990; Castel et al., 1994; Tanganelli et al., 1994; Wagstaff et al., 1996). NT reduces the affinity of $\mathrm{D}_{2}$ agonist binding sites and possibly their transduction through a receptor-receptor interaction at both presynaptic and postsynaptic levels in the striatum (Agnati et al., 1983; von Euler and Fuxe, 1987; Fuxe et al., 1992a,b), which provides the basis for its cataleptic profile (Shibata et al., 1987; Da-Silva et al., 1989; Shandra et al., 1994). Although most of the studies were focused on the modulation of the dopaminergic systems by NT, recent findings suggested that NT interacts with other neurotransmitters. In this respect, it was demonstrated that NT is localized in some striatal GABAergic neurons, and NT receptors were detected in striatal neurons (Fuxe et al., 1992a). Moreover, microdialysis studies demonstrated that NT regulates neuronal elements in the striatum postjunctionally to the afferent dopamine terminals such as striatal glutamatergic afferent terminals 
(Ferraro et al., 1995) and striatal GABAergic efferents (Fuxe et al., 1992b; O'Connor et al., 1992). These two neurotransmitters are present in pathways that represent important links in the basal ganglia-thalamocortical circuit and that provide a neuronal network through which the motor cortex executes motor function. However, the precise functional role of striatal NT in regulating glutamate and GABA transmission in the basal ganglia still remains unclear.

In the present study, the role of striatal NT receptor activation and blockade in the regulation of striatal and pallidal glutamate and GABA transmission was investigated.

\section{MATERIALS AND METHODS}

Materials. Male adult Sprague Dawley rats (300-350 gm) were purchased from Stefano Morini (Reggio Emilia, Italy), kept under regular lighting conditions (12 hr light/dark cycle), and given food and water ad libitum.

NT (Peninsula Laboratories, Belmont, CA) and (-)-bicuculline methochloride (Sigma, St. Louis, MO) were dissolved in Ringer's solution just before testing and used only once. 2-[(1-(7-chloro-4-quinolinyl)5-(2,6-dimethoxy-phenyl)pyrazol-3-yl)carboxyla mino] tricyclo) 3.3.1.1. ${ }^{3.7}$ ) - decan-2 - carboxylic acid (SR 48692; Sanofi Recherche, Montpellier, France) was dissolved in dimethylsulfoxide and intraperitoneally injected or diluted in the Ringer's solution (final concentration of dimethylsulfoxide was $<0.001 \%$ ). When required, the DMSO vehicle was perfused in either control animals or in combination with NT perfusion.

All other chemicals used were of analytical grade and purchased from Sigma or Merck (Darmstadt, Germany).

Surgery. The animals, kept under halothane anesthesia (1.5\% mixture of halothane and air), were mounted in a David Kopf stereotaxic frame with the upper incisor bar set at $-2.5 \mathrm{~mm}$ below the interaural line. After exposing the skull and drilling two holes, two microdialysis probes of concentric design (molecular weight cutoff, 20,000 Da; CMA 12; Carnegie Medicin) were implanted. One probe was implanted into the right or the left striatum (outer diameter, $0.5 \mathrm{~mm}$; length of dialyzing membrane, $4 \mathrm{~mm}$ ), and the other was implanted into the ipsilateral GP (outer diameter, $0.5 \mathrm{~mm}$; length of dialyzing membrane, $2 \mathrm{~mm}$ ). The coordinates relative to the bregma were as follows: striatum, anterior $(\mathrm{A}),+0.3$; lateral $(\mathrm{L}), \pm 3.1$; ventral $(\mathrm{V}),-8.5 ; \mathrm{GP}, \mathrm{A},-1.3 ; \mathrm{L}, \pm 3.3 ; \mathrm{V},-8.0$ (Paxinos and Watson, 1982). In a final set of experiments, the animals were implanted with a microdialysis probe into the GP and a stainless steel guide cannula (22 gauge, C313G; Plastics One, Roanoke, VA) into an area overlying the ipsilateral STN (A, -3.9; L, $\pm 2.2 ; \mathrm{V},-7.5)$ (Rosales et al., 1997). After the implantation, the probes were permanently secured to the skull with methacrylic cement, and $36 \mathrm{hr}$ later the release experiment was performed.

Experimental protocol. On the day of the release experiment, the probes were perfused with Ringer's solution (in $\mathrm{mM}$ : $\mathrm{Na}^{+} 147, \mathrm{~K}^{+} 4$, $\mathrm{Ca}^{2+} 1.4, \mathrm{Cl}^{-} 156$, and glucose 2.7$)$ at a constant flow rate $(2 \mu \mathrm{l} / \mathrm{min})$ by using a microinfusion pump. The striatal probe was used for both local perfusion with the NT peptide and its receptor antagonist and the collection of samples for extracellular glutamate and GABA levels, whereas the pallidal probe was used for the collection of samples for extracellular glutamate and GABA levels. When required, the pallidal probe was also used for the local perfusion with the $\mathrm{GABA}_{\mathrm{A}}$ receptor antagonist (-)-bicuculline.

The collection of perfusate samples commenced $300 \mathrm{~min}$ after the onset of perfusion to achieve stable dialysis glutamate levels, and perfusates were collected every $30 \mathrm{~min}$. After three stable basal values were obtained, NT was included into the striatal perfusate medium for $60 \mathrm{~min}$. This medium was then replaced with the original perfusate, and another four samples were collected $(120 \mathrm{~min})$ from both the striatal and pallidal probes. When required, the NT receptor antagonist SR48692 (Gully et al., 1993) was intraperitoneally injected or intrastriatally perfused $20-25$ min before the peptide.

When the animals implanted with the guide cannula showed stable pallidal glutamate levels (three samples), an injection cannula (28 gauge, C313I; Plastics One) was carefully inserted into the guide cannula to allow the intrasubthalamic injection of (-)-bicuculline $(10 \mathrm{pmol} / 100 \mathrm{nl}$, $30 \mathrm{sec}$ ) or saline by using an infusion pump. The microdialysis probe placed in the ipsilateral GP recorded dialysate glutamate release. In view of previous electrophysiological data (Soltis et al., 1994) demonstrating a short-lasting effect (10 min) of intrasubthalamic (-)-bicuculline inf usion on pallidal neuronal firing rate, the pallidal samples were, in this set of experiments, collected every $15 \mathrm{~min}$.

At the end of each experiment, the brain was removed from the skull, and the position of the probes and the cannula was carefully verified in $30-\mu \mathrm{m}$-thick coronal cryostat sections. Only those animals in which both probes were correctly located were included in this study.

The experimental protocols performed in the present study were approved by Ministero della Sanitá (license 111/94-B).

Glutamate and GABA analyses. Endogenous glutamate was quantified using an HPLC-fluorimetric detection system, including precolumn derivatization $o$-phtaldialdehyde reagent and a Chromsep 5 (C18) column (Calò et al., 1997). The mobile phase consisted of $0.1 \mathrm{M}$ sodium acetate, $10 \%$ methanol, and $2.5 \%$ tetrahydrofurane, $\mathrm{pH}$ 6.5. The limit of detection for glutamate was $30 \mathrm{fmol} / \mathrm{sample}$.

Endogenous GABA was quantified using an HPLC-electrochemical detection system, including a precolumn derivatization with an $o$-phtaldialdehyde- $t$-butylthiol reagent and a reverse-phase column (Nucleosil 3, C18) (Kehr and Ungerstedt, 1989). The mobile phase consisted of $0.15 \mathrm{M}$ sodium acetate, $0.1 \mathrm{~mm}$ EDTA, pH 5.4, and 50\% acetonitrile. The limit of detection for GABA was $20 \mathrm{fmol} / \mathrm{sample}$.

The inclusion of NT or the NT receptor antagonist SR48692 in the striatal perfusion medium did not alter the $\mathrm{pH}$ of the perfusion medium or interfere with the qualitative and quantitative HPLC assay both of glutamate and GABA.

Statistical analysis. Data from individual time points are reported as percentages of the mean of the three basal samples before treatment. The data were calculated as mean \pm SEM, and the significance with regard to the peak effects (maximal responses) is shown in the figures. In addition, the area created by the curve, which mainly reflects the duration of the effect under the experimental period, was calculated for each animal. The area values (overall effects) were calculated as percentages of changes in basal value over time ( $\Delta$ basal percentage $\times$ time) by using the trapezoidal rule. The statistical analysis was performed by one-way ANOVA, followed by the Newman-Keuls test for multiple comparisons. The nonparametric Spearman coefficient was used for correlations.

\section{RESULTS}

\section{Effects of intrastriatal perfusion with NT on striatal and pallidal glutamate release}

Basal dialysate glutamate levels in the neostriatum and GP of control rats were $0.292 \pm 0.033$ and $0.168 \pm 0.014 \mu \mathrm{M}(n=11)$, respectively, and remained constant over the duration of the release experiment $(270 \mathrm{~min})$. Intrastriatal perfusion with NT (100 and $300 \mathrm{~nm}$ ) produced a rapid and concentration-related increase in both striatal and pallidal glutamate release (striatum, $155 \pm 9$ and $179 \pm 8 \%$, respectively; GP, $144 \pm 8$ and $169 \pm 9 \%$, respectively).

At the lower 1 and $10 \mathrm{~nm}$ concentrations, the peptide did not affect striatal and pallidal glutamate release (Fig. 1 $A, B$ ).

\section{Effects of systemic injection and intrastriatal perfusion of the NT receptor antagonist SR48692 on the NT-induced increase in striatal and pallidal glutamate release}

\section{Striatal glutamate release}

Neither the 0.1 nor the $0.2 \mathrm{mg} / \mathrm{kg}$ intraperitoneal dose of the selective nonpeptide NT receptor antagonist SR48692 affected basal striatal glutamate levels (Fig. 2A). However, when SR48692 was administered $25 \mathrm{~min}$ before intrastriatal NT (100 nM) at the 0.1 and $0.2 \mathrm{mg} / \mathrm{kg}$ doses, it dose-dependently counteracted the increase in glutamate release induced by the peptide (Fig. $2 B$ ).

\section{Pallidal glutamate release}

SR48692 (0.1 and $0.2 \mathrm{mg} / \mathrm{kg}$, i.p.) did not affect basal glutamate levels from the GP of the awake rat (Fig. $3 A$ ). Similarly to the striatum, when SR48692 was administered 25 min before intrastriatal NT (100 nM) at the 0.1 and $0.2 \mathrm{mg} / \mathrm{kg}$ doses, it dosedependently counteracted the increase in glutamate release induced by the peptide (Fig. 3B). 

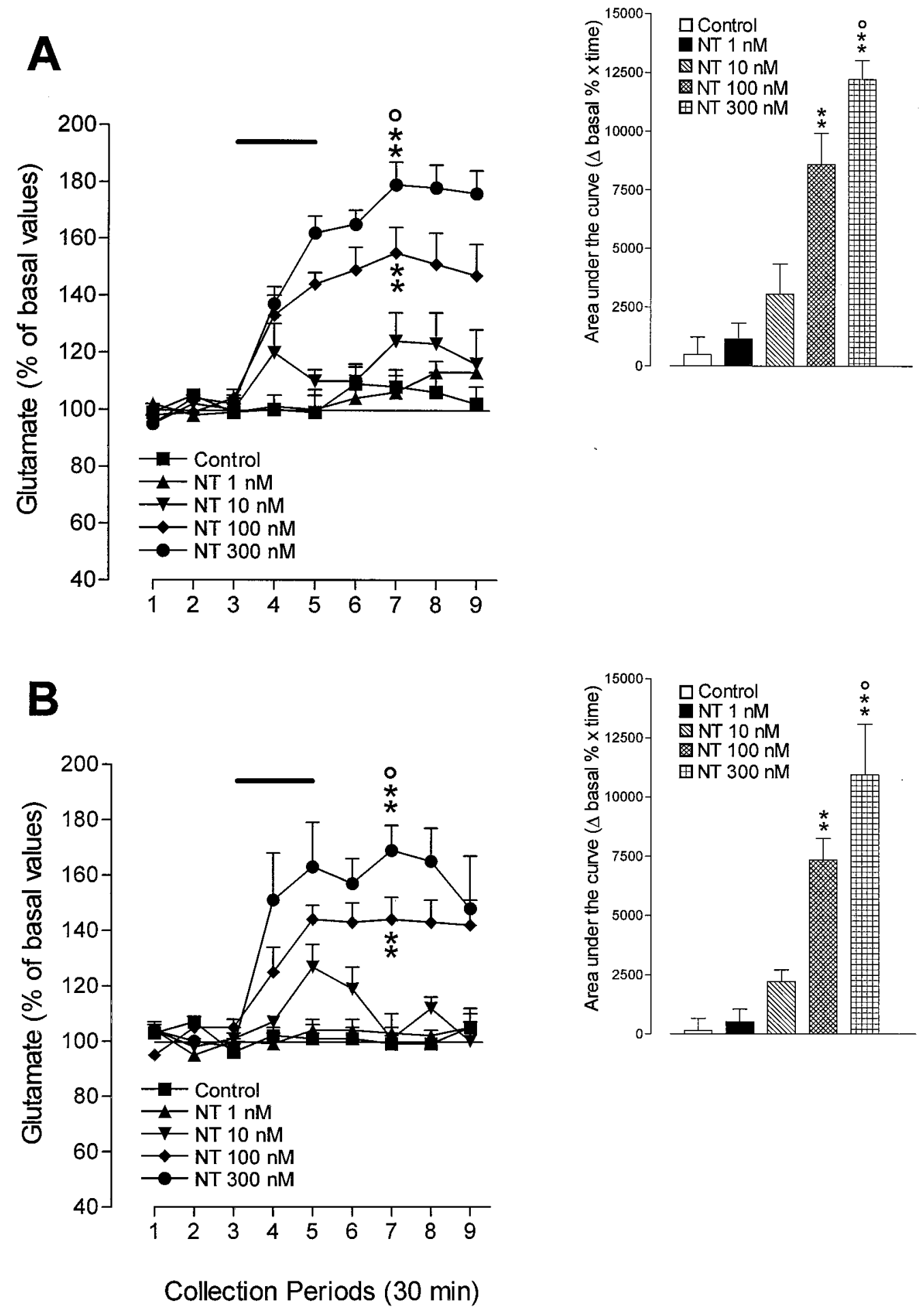

Figure 1. Effects of intrastriatal perfusion with NT on striatal $(A)$ and pallidal $(B)$ glutamate release in the awake rat. Solid bars indicate the period of perfusion with the peptide $(60 \mathrm{~min})$. The results are expressed as percentage of the mean of the three basal values before treatment. For absolute glutamate basal levels, see Results. Each point represents the mean \pm SEM of five to seven animals. Control rats were perfused with normal Ringer's perfusion medium throughout the experiment. The histograms of the areas under the curves, calculated as percentage of changes in basal value over time ( $\Delta$ basal percentage $\times$ time) by using the trapezoidal rule, are shown on the right. ${ }^{* *} p<0.01$ significantly different from control; ${ }^{\circ} p<0.05$ significantly different from $100 \mathrm{~nm}$ NT according to one-way ANOVA, followed by the Newman-Keuls test for multiple comparisons.

The effects of the intrastriatal perfusion with SR48692 (100 nM) alone and/or in combination with NT (100 nM) on pallidal glutamate release were also studied. The intrastriatal application of the NT receptor antagonist or the vehicle (DMSO, $0.001 \%$ ) by themselves did not affect basal pallidal glutamate release. However, when SR48692 was included in the striatal perfusion medium 20 min before NT (100 nM), it fully counteracted the peptide-induced enhancement of pallidal glutamate release (Fig. 

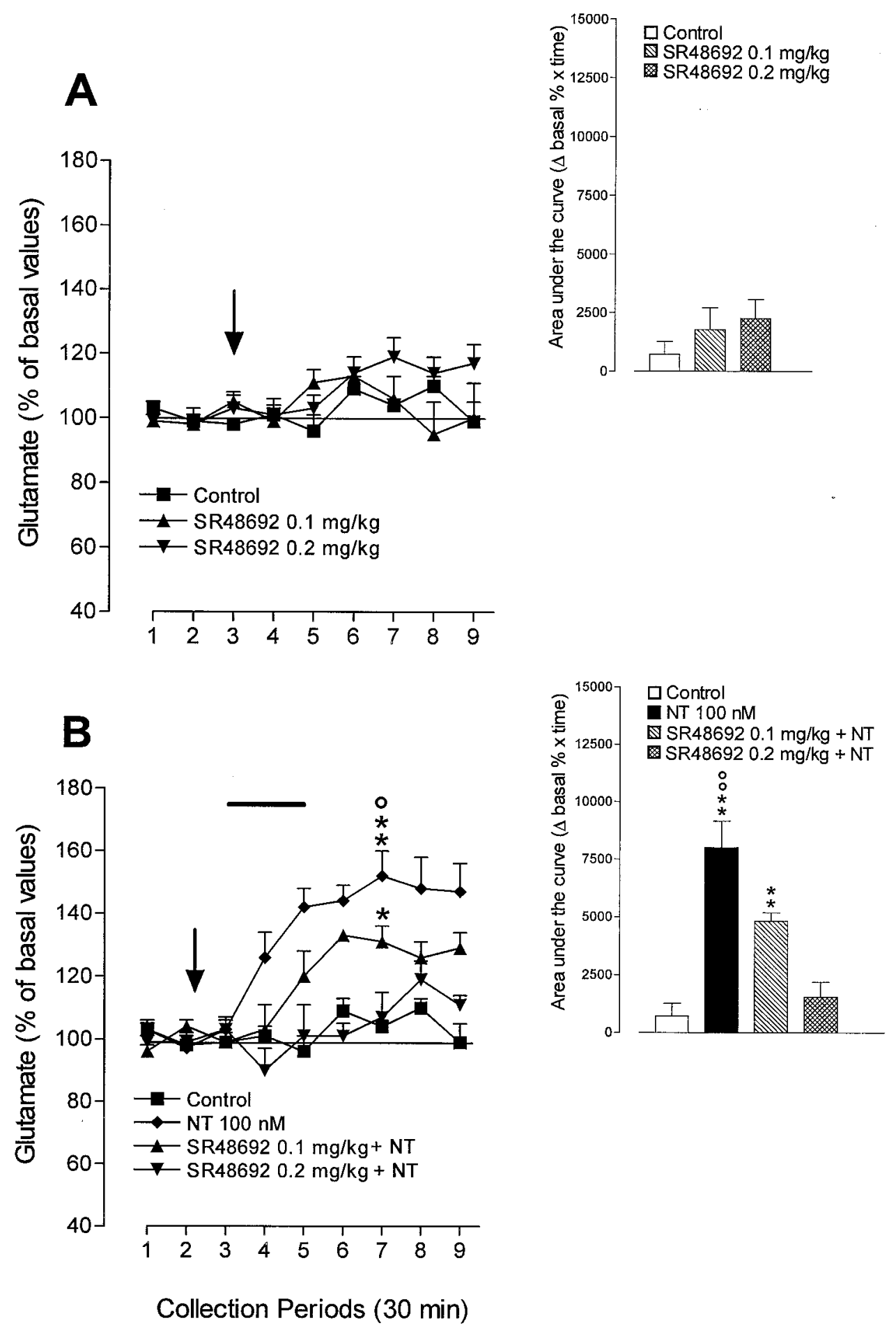

Figure 2. Effects of intraperitoneal injection of the NT receptor antagonist SR48692 on basal $(A)$ and NT-induced (100 nM) $(B)$ glutamate release from the striatum of the awake rat. Arrows indicate the injection of SR48692, whereas the solid bar in $B$ indicates the period of perfusion with the peptide (60 $\mathrm{min})$. The results are expressed as percentage of the mean of the three basal values before treatment. Each point represents the mean \pm SEM of five or six animals. The histograms of the areas under the curves, calculated as percentage of changes in basal value over time $(\Delta$ basal percentage $\times$ time $)$ by using the trapezoidal rule, are shown on the right. ${ }^{*} p<0.05,{ }^{*} p<0.01$ significantly different from control; ${ }^{\circ} p<0.05,{ }^{\circ} p<0.01$ significantly different from $0.1 \mathrm{mg} / \mathrm{kg} \mathrm{SR} 48692$ plus NT according to one-way ANOVA, followed by the Newman-Keuls test for multiple comparisons.

4). The inclusion of DMSO $(0.001 \%)$ to the striatal perfusion medium 20 min before NT (100 nM) did not modify the effects of the peptide on striatal and pallidal glutamate release (data not shown).

\section{Effects of intrastriatal neurotensin perfusion on striatal and pallidal GABA release}

Basal striatal and pallidal GABA levels measured in $30 \mathrm{~min}$ dialysate fractions were $18.71 \pm 2.1$ and $9.01 \pm 0.93 \mathrm{nM}(n=11)$, 

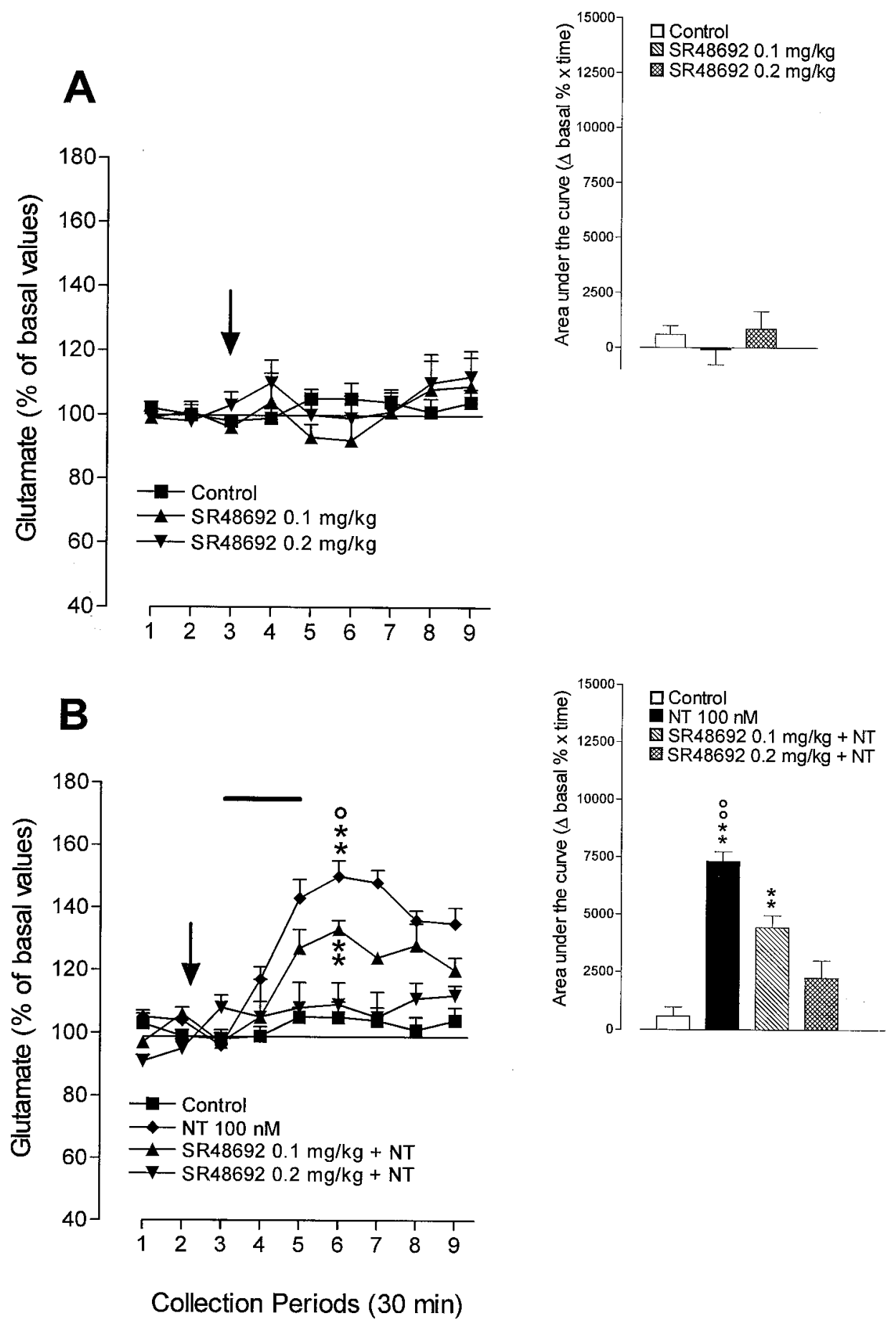

Figure 3. Effects of intraperitoneal injection of the NT receptor antagonist SR48692 on basal $(A)$ and NT-induced $(100 \mathrm{nM})(B)$ glutamate release from the GP of the awake rat. Arrows indicate the injection of SR48692. NT was perfused into the striatum for 60 min (solid bar). The results are expressed as percentage of the mean of the three basal values before treatment. Each point represents the mean \pm SEM of five or six animals. The histograms of the areas under the curves, calculated as percentage of changes in basal value over time ( $\Delta$ basal percentage $\times$ time) by using the trapezoidal rule, are shown on the right. ${ }^{* *} p<0.01$ significantly different from control; ${ }^{\circ} p<0.05,{ }^{\circ} p<0.01$ significantly different from $0.1 \mathrm{mg} / \mathrm{kg}$ SR $48692 \mathrm{plus} \mathrm{NT}$ according to one-way ANOVA, followed by the Newman-Keuls test for multiple comparisons.

respectively, and remained stable over the duration of the experiment. Intrastriatal NT (1, 10, 100, and $300 \mathrm{~nm})$ was associated with a concentration-dependent increase in both striatal and pallidal GABA release (striatum, $106 \pm 6,100 \pm 3,141 \pm 6$, and $166 \pm 11 \%$, respectively; GP, $107 \pm 6,110 \pm 9,130 \pm 5$, and $157 \pm 8 \%$, respectively) (Fig. $5 A, B)$.

\section{Effects of systemic injection of the NT receptor antagonist SR48692 on the NT-induced increase in striatal and pallidal GABA release}

The selective NT receptor antagonist SR48692 (0.1 and 0.2 $\mathrm{mg} / \mathrm{kg}$, i.p.) did not affect basal striatal or pallidal GABA levels, although a slight decrease in striatal and pallidal GABA release 

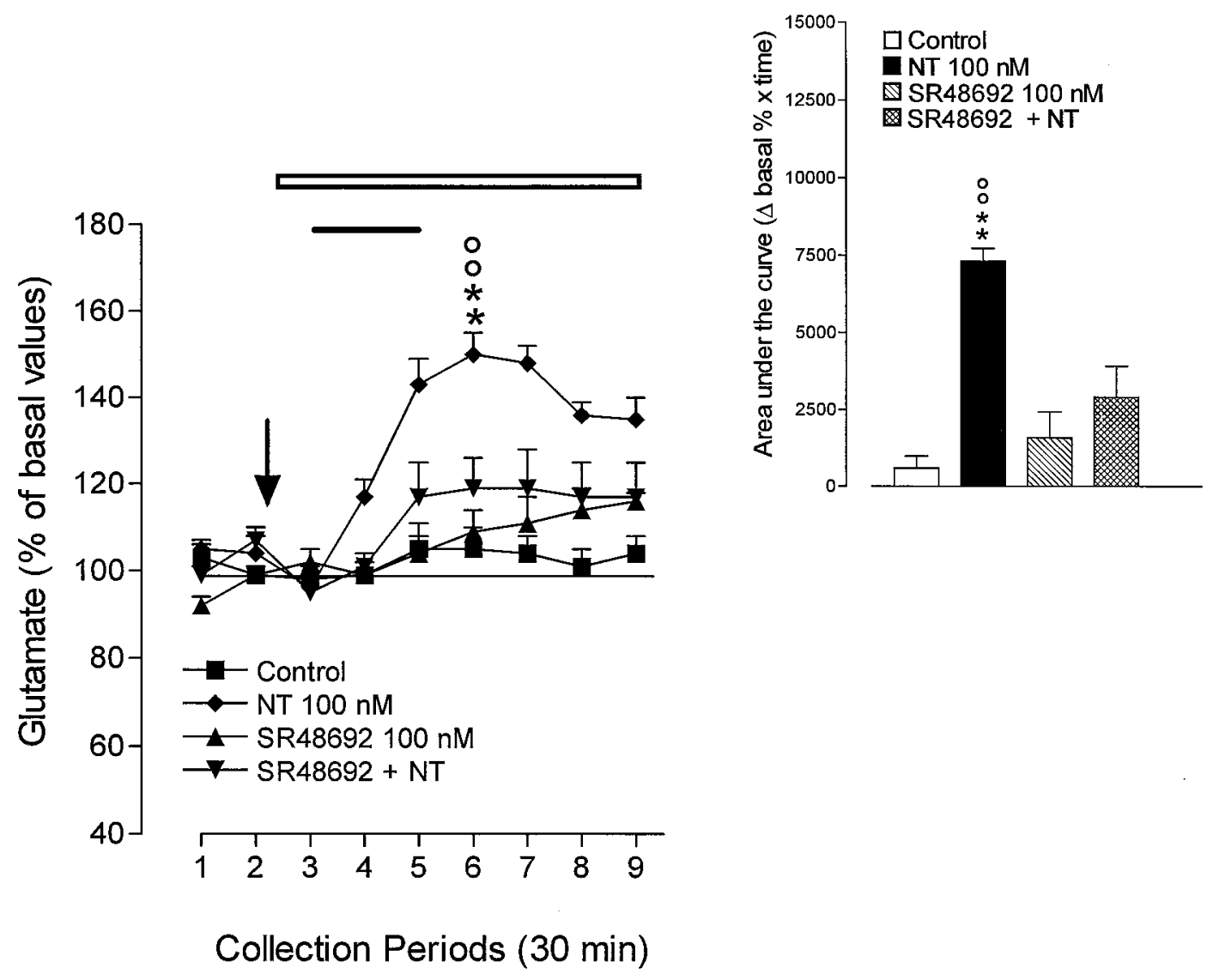

Figure 4. Effects of intrastriatal perfusion with the NT receptor antagonist SR48692 on NT-induced (100 nM) glutamate release from the GP of the awake rat. NT was perfused into the striatum for $60 \mathrm{~min}$ (solid bar), whereas SR48692 was added to the striatal perfusion medium 20 min before the peptide and maintained until the end of the experiment (open bar). The results are expressed as percentage of the mean of the three basal values before treatment. Each point represents the mean \pm SEM of five or six animals. The histograms of the areas under the curves, calculated as percentage of changes in basal value over time ( $\Delta$ basal percentage $\times$ time) by using the trapezoidal rule, are shown on the right. **p $<0.01$ significantly different from control; ${ }^{\circ} p<0.01$ significantly different from $100 \mathrm{~nm}$ SR48692 plus NT according to one-way ANOVA, followed by the Newman-Keuls test for multiple comparisons.

was observed 120-150 min after SR48692 (0.2 mg/kg, i.p.) injection (Figs. $6 A, 7 A$ ). However, when SR48692 was administered 25 min before intrastriatal NT (100 nM) at the 0.1 and $0.2 \mathrm{mg} / \mathrm{kg}$ doses, it dose-dependently counteracted the increase in GABA release induced by the peptide (Figs. 6B, 7B).

\section{Effects of (-)-bicuculline injected into the subthalamic nucleus on pallidal glutamate release and (-)- bicuculline perfused into the globus pallidus on the NT-induced increase in pallidal glutamate release}

In view of the above results and to determine whether the intrastriatal NT-induced increase in pallidal glutamate release was mediated by a reduction in the inhibitory striatopallidal-STN GABA pathway resulting in a disinhibition of the excitatory STN-SNr and STN-GP glutamate drives, two additional experiments were performed.

First, to support the existence of a tonic GABA inhibition of the excitatory STN-GP glutamate neurons, the $\mathrm{GABA}_{\mathrm{A}}$ antagonist (-)-bicuculline was directly injected into the STN nucleus, and the effect on pallidal glutamate release was evaluated. As shown in Figure $8 A$, the inf usion of $(-)$-bicuculline $(10 \mathrm{pmol} / 100$ $\mathrm{nl}, 30 \mathrm{sec}$ ) into the subthalamic nucleus induced a rapid increase in pallidal glutamate release, whereas a control injection with Ringer's solution was without effect.

Second, the effects of intrapallidal perfusion with (-)- bicuculline $(1 \mu \mathrm{M})$ were evaluated on the increase of pallidal glutamate release induced by the intrastriatal NT (100 nM) perfusion. As shown in Figure $8 B$, the $\mathrm{GABA}_{\mathrm{A}}$ antagonist perfused 20 min before NT fully counteracted the intrastriatal NTinduced increase in pallidal glutamate release. When perfused alone, (-)-bicuculline $(1 \mu \mathrm{M})$ did not affect pallidal glutamate release. These results prompted us to further analyze the existence of a possible correlation between the effects of NT on pallidal glutamate and GABA release by using the nonparametric Spearman test. As shown in Figure 9, by evaluating the area under the curve values, a significant correlation was found.

\section{DISCUSSION}

It is well known that the complex neuronal interactions that take place in the basal ganglia play a crucial role in the regulation of the motor activity. The GABAergic striatopallidal pathway represents the first link in the so-called striatal indirect efferent pathway to the $\mathrm{SNr}$, and its activation is associated with an enhancement in STN glutamatergic input to the SNr, an increase in the inhibitory regulation of the motor thalamus, and a reduced excitatory drive on the motor cortex (Alexander and Crutcher, 1990). Previous studies indicate that NT exerts a modulatory action on the neuronal transmission in the basal ganglia, particularly on presynaptic and postsynaptic elements of the nigrostri- 


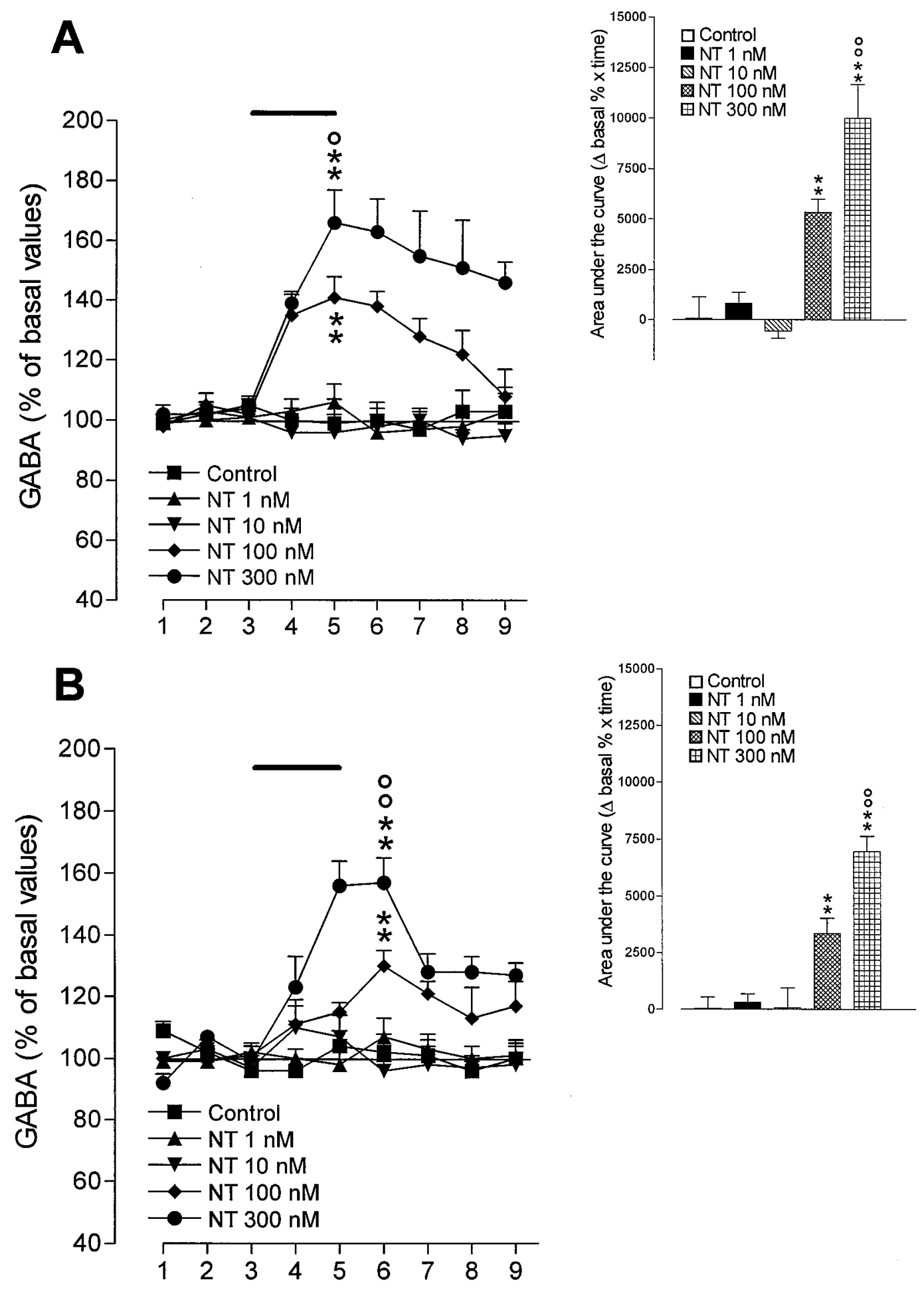

Collection Periods (30 min)

Figure 5. Effects of intrastriatal perfusion with NT on striatal $(A)$ and pallidal $(B)$ GABA release in the awake rat. Solid bars indicate the period of perfusion with the peptide $(60 \mathrm{~min})$. The results are expressed as percentage of the mean of the three basal values before treatment. For absolute GABA basal levels, see Results. Each point represents the mean \pm SEM of five to seven animals. Control rats were perfused with normal Ringer's perfusion medium throughout the experiment. The histograms of the areas under the curves, calculated as percentage of changes in basal value over time $(\Delta$ basal percentage $\times$ time) by using the trapezoidal rule, are shown on the right. ${ }^{* *} p<0.01$ significantly different from control; ${ }^{\circ} p<0.05,{ }^{\circ} p<0.01$ significantly different from 100 nM NT according to one-way ANOVA, followed by the Newman-Keuls test for multiple comparisons. 

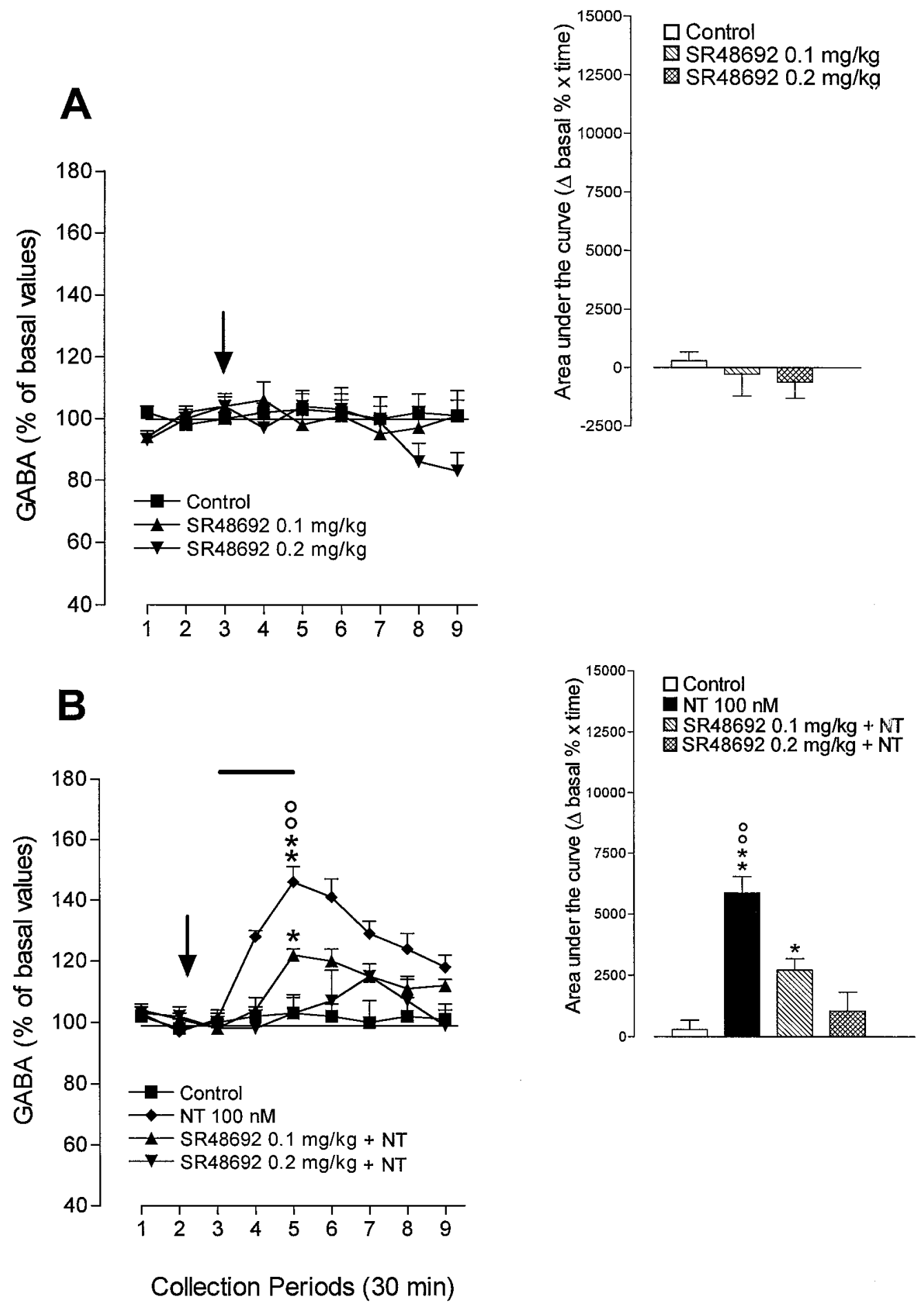

Figure 6. Effects of intraperitoneal injection of the NT receptor antagonist SR48692 on basal $(A)$ and NT-induced (100 nM) (B) GABA release from the striatum of the awake rat. Arrows indicate the injection of SR48692, whereas the solid bar indicates the period of perfusion with the peptide (60 min). The results are expressed as percentage of the mean of the three basal values before treatment. Each point represents the mean \pm SEM of five or six animals. The histograms of the areas under the curves, calculated as percentage of changes in basal value over time $(\Delta$ basal percentage $\times$ time $)$ by using the trapezoidal rule, are shown on the right. ${ }^{*} p<0.05,{ }^{*} p<0.01$ significantly different from control; ${ }^{\circ} p<0.01$ significantly different from $0.1 \mathrm{mg} / \mathrm{kg}$ SR48692 plus NT according to one-way ANOVA, followed by the Newman-Keuls test for multiple comparisons.

atal dopaminergic pathway (Fuxe et al., 1992b). In the present study, dual-probe microdialysis was used to investigate the functional role of the striatal NT receptor on striatal and pallidal amino acid-ergic transmission by monitoring simultaneously alterations in glutamate and GABA release induced by the striatal
NT receptor activation and blockade. In addition, in view of the results obtained, we investigated the role of pallidal GABA regulation in the STN-GP glutamate pathway.

Extracellular striatal glutamate levels are derived in part from the terminals of cortical and thalamic afferents, whereas extracel- 

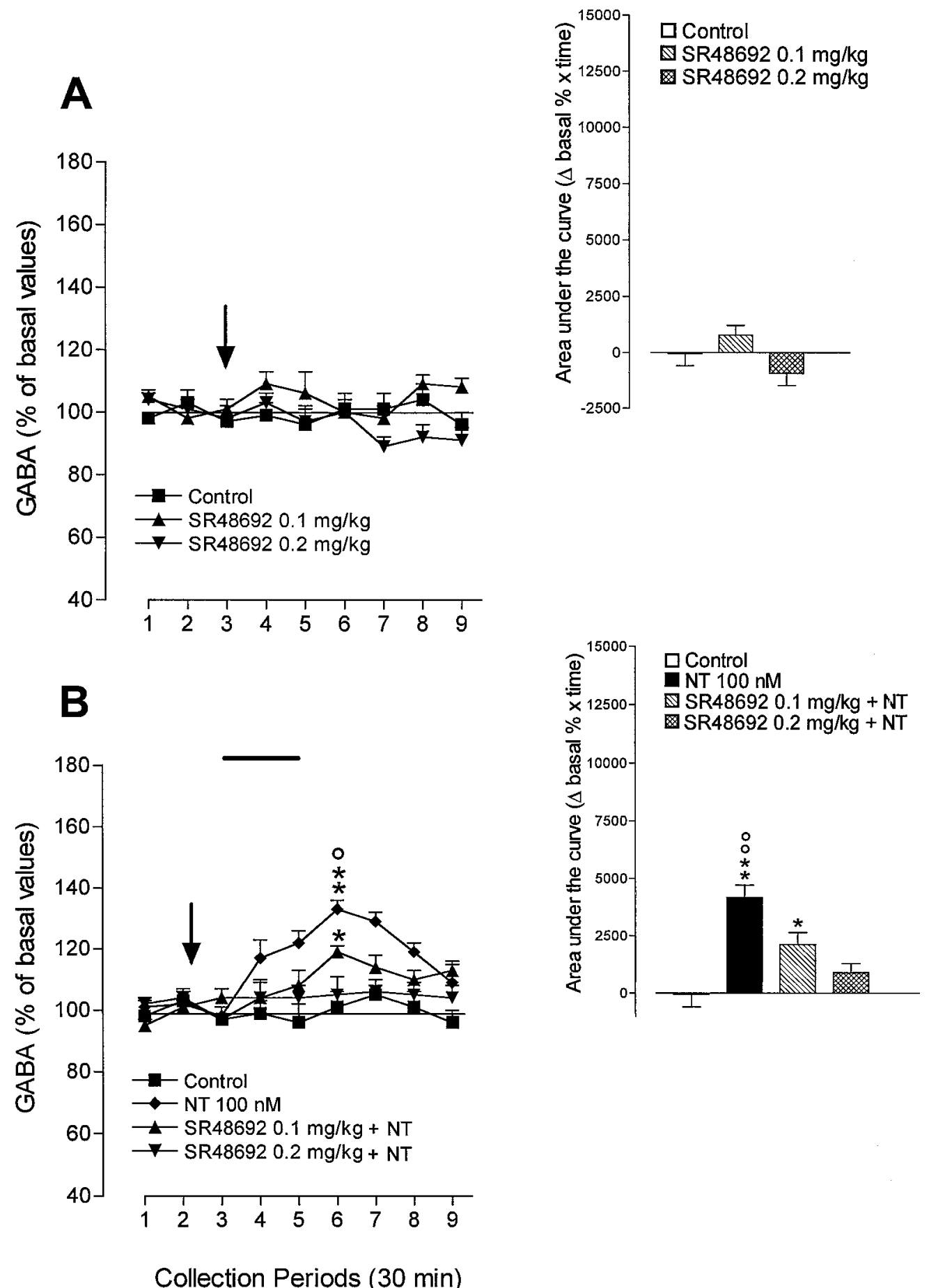

Figure 7. Effects of intraperitoneal injection of the NT receptor antagonist SR48692 on basal $(A)$ and NT-induced (100 nM) $(B)$ GABA release from the GP of the awake rat. Arrows indicate the injection of SR48692. NT was perfused into the striatum for 60 min (solid bar). The results are expressed as percentage of the mean of the three basal values before treatment. Each point represents the mean \pm SEM of five or six animals. The histograms of the areas under the curves, calculated as percentage of changes in basal value over time ( $\Delta$ basal percentage $\times$ time) by using the trapezoidal rule, are shown on the right. ${ }^{*} p<0.05,{ }^{* *} p<0.01$ significantly different from control; ${ }^{\circ} p<0.05,{ }^{\circ} p<0.01$ significantly different from $0.1 \mathrm{mg} / \mathrm{kg}$ SR 48692 plus NT according to one-way ANOVA, followed by the Newman-Keuls test for multiple comparisons.

lular striatal GABA levels are derived in part from local interneurons and the axon collaterals of the striopallidal and strionigral projection neurons (Sirinathsinghji and Heavens, 1989; Parent and Hazrati, 1995). Extracellular pallidal glutamate levels are derived from the terminals of the STN-GP pathway, whereas pallidal GABA levels are derived from the terminals of the striopallidal pathway or from local axon collaterals of pallidal GABA projection neurons (Park et al., 1982; Scheel-Kruger, 1986; Pasik et al., 1987; Parent and Hazrati, 1995).

The present results clearly indicate that striatal and pallidal glutamate and GABA release is increased after striatal NT receptor activation and provide strong evidence that the increase in 

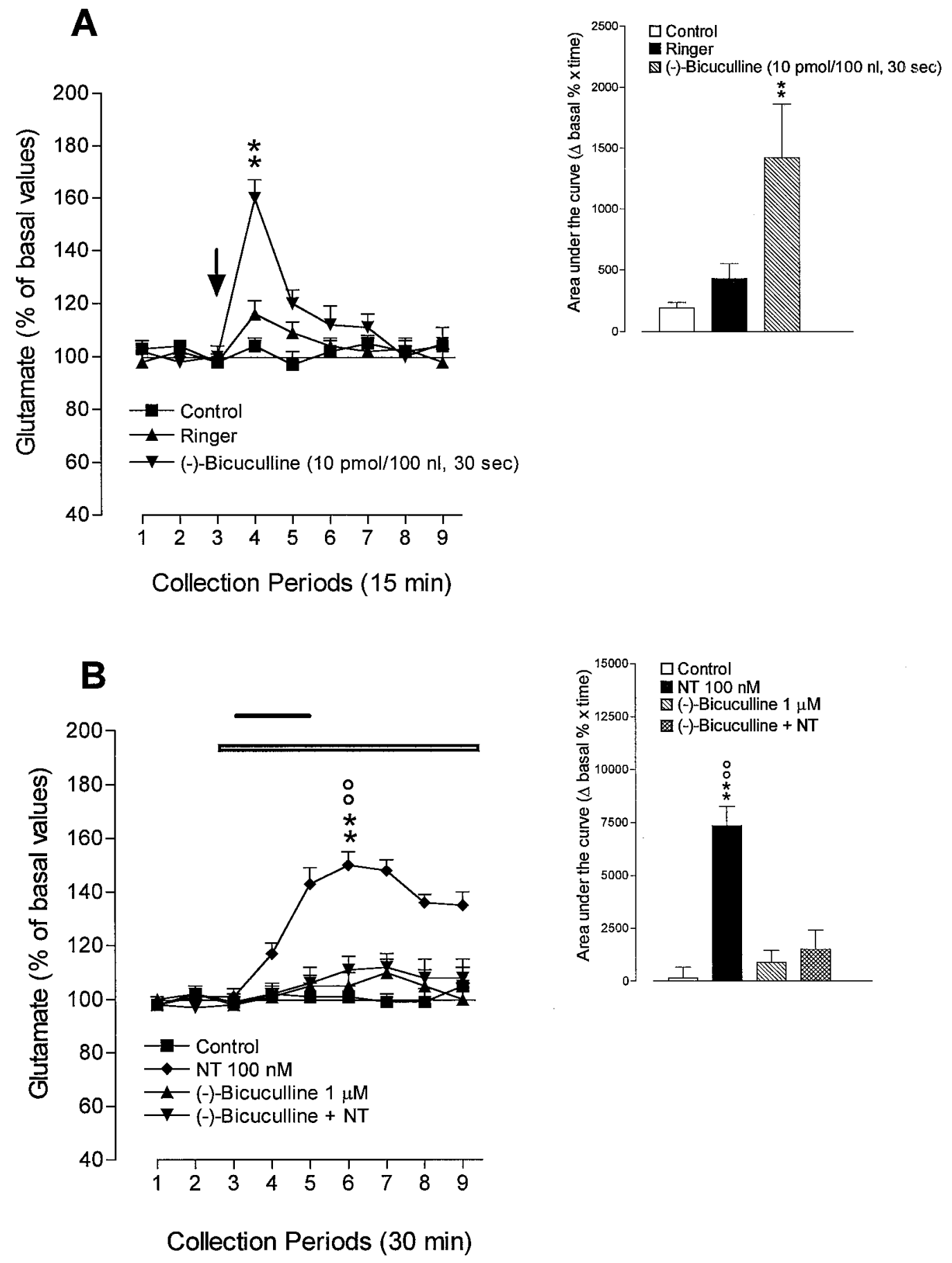

Figure 8. A, Effects of intrasubthalamic injection of the $\mathrm{GABA}_{\mathrm{A}}$ receptor antagonist (-)-bicuculline on basal glutamate release from the GP of the awake rat. $(-)$-Bicuculline $(10 \mathrm{pmol} / 100 \mathrm{nl}, 30 \mathrm{sec})$ or saline $(30 \mathrm{sec})$ was injected (arrow) into the subthalamic nucleus by using an inf usion pump. Control rats were implanted but did not receive any infusion during the experiment. $B$, Effects of intrapallidal perfusion with the $\mathrm{GABA}_{\mathrm{A}}$ receptor antagonist (-)-bicuculline on NT-induced (100 nM) glutamate release from the GP of the awake rat. NT was perfused into the striatum for 60 min (solid bar), whereas (-)-bicuculline was added to the pallidal perfusion medium 20 min before the peptide and maintained until the end of the experiment (open bar). The results are expressed as percentage of the mean of the three basal values before treatment. Each point represents the mean \pm SEM of six to nine animals. The histograms of the areas under the curves, calculated as percentage of changes in basal value over time $(\Delta$ basal percentage $\times$ time) by using the trapezoidal rule, are shown on the right. ${ }^{* *} p<0.01$ significantly different from control; ${ }^{\circ} p<0.01$ significantly different from (-)-bicuculline plus NT according to one-way ANOVA, followed by the Newman-Keuls test for multiple comparisons.

pallidal glutamate release is mediated via increased excitatory glutamatergic STN-GP transmission. Furthermore, the counteraction of these effects by the systemic and local administration of the NT receptor antagonist SR48692 (Gully et al., 1993; Betan- cour et al., 1995) suggests that the striatal NT receptor regulates the indirect pathway in the basal ganglia either directly via somatodendritic NT receptors on the GABA neurons and/or indirectly via NT receptors on corticostriatal and/or thalamostriatal 


\section{Globus Pallidus}

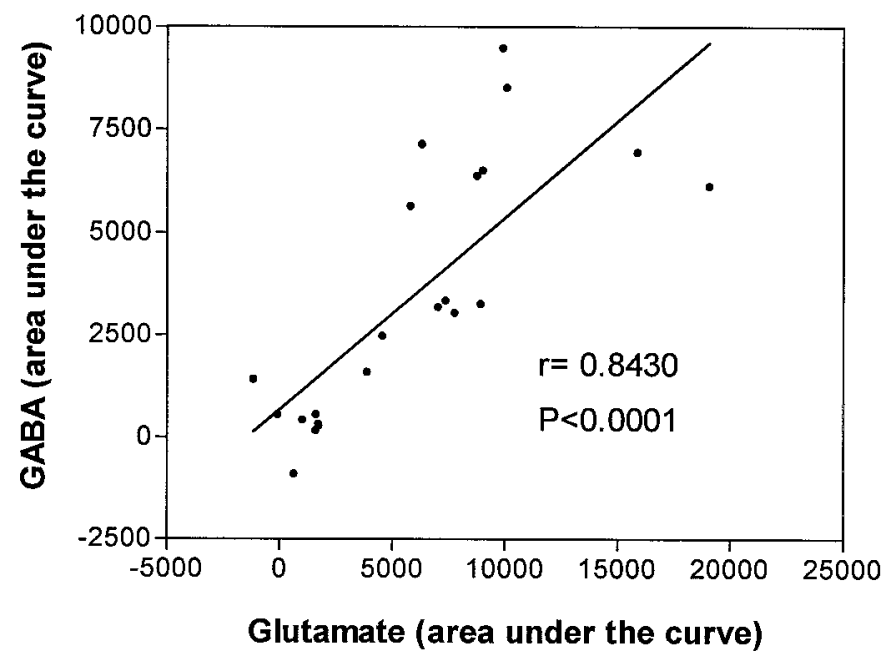

Figure 9. A significant positive correlation between intrastriatal NTinduced (1-300 $\mathrm{nM})$ alterations in pallidal GABA and glutamate release was found by evaluating the area under the curve values plotted on the $y$ and $x$-axes, respectively. The Spearman correlation coefficient was used.

glutamate terminals (O'Connor et al., 1992; Ferraro et al., 1995, 1997). Although these neurons have not been extensively shown to possess NT receptors, this hypothesis is supported by the work of Masuo et al. (1990), who suggested that a certain proportion of NT receptors may be located on striatal projection neurons. Nevertheless, in view of studies (Quirion et al., 1985, 1992) demonstrating the presence of high-affinity NT receptors primarily on dopaminergic terminals and possibly on cholinergic interneurons in the striatum, it cannot be excluded that the NTinduced effects observed in the present study can also involve actions on other transmitters. However, O'Connor et al. (1992) and Steinberg et al. (1995) have shown that striatal acetylcholine release is not modulated by NT. Furthermore, the activation of the high-affinity NT receptor on the dopaminergic terminal by increasing striatal dopamine release (Fuxe et al., 1992b) would result in an enhancement of the dopamine $\mathrm{D}_{2}$ receptor-mediated inhibition of striopallidal GABA release rather than the observed increase in striopallidal GABA transmission. Together, these findings suggest that some NT receptors, possibly located on the striopallidal GABA projection neurons and/or their glutamatergic inputs, could mediate the observed effects of intrastriatal NT on GABA and glutamate release, although other mechanism(s) cannot be definitively excluded.

The present microdialysis results confirm those of a previous study that showed that the intrastriatal NT-induced increase in pallidal GABA release is counteracted by intrastriatal administration of the NT receptor antagonist SR48692 (Ferraro et al., 1997) and go on to show that intrastriatal NT concentration dependently increases both striatal and pallidal glutamate release. The finding of a counteraction of the NT-induced increase in pallidal glutamate release after intrapallidal $\mathrm{GABA}_{\mathrm{A}}$ receptor blockade with (-)-bicuculline provides strong evidence that the NT receptor activation in the striatum regulates pallidal glutamatergic transmission via increased striopallidal GABA transmission, probably by reducing the activity of those GABAergic neurons projecting to the STN and thus disinhibiting the excitatory glutamatergic STN-SNr efferents, which sends axon collat- erals to the GP (Alexander and Crutcher, 1990) (Fig. 10). The intrapallidal (-)-bicuculline perfusion was used to antagonize the intrastriatal NT-induced effects on pallidal glutamate release, because previous studies demonstrated the role of $\mathrm{GABA}_{\mathrm{A}}$ receptor activation in modulating the pallidal output system toward the STN (Kita, 1992; Amalric et al., 1994). The existence of a tonic pallidal GABA-mediated inhibition of excitatory STN-GP neurons is further supported by the demonstration that intraSTN inf usion of (-)-bicuculline induced a significant increase in pallidal glutamate release. This finding is in line with a previous electrophysiological study (Soltis et al., 1994), which demonstrated that the infusion of bicuculline into the STN induced an increase in the firing rate of pallidal neurons and with the in situ study of Delfs et al. (1995), who showed that pallidal GAD mRNA is regulated by an excitatory input from the STN. Finally, this pallidal GABA-glutamate interaction is strengthened by the positive correlation found between the effects of NT on pallidal GABA and glutamate release.

In view of converging evidence suggesting that behavioral catalepsy in rodents and akinesia in humans is mediated by increased striopallidal GABA transmission (Scheel-Kruger, 1986; Drew et al., 1990; Osborne et al., 1994), these findings suggest that the cataleptic profile of NT (Shibata et al., 1987; Da-Silva et al., 1989; Shandra et al., 1994) may be explained by its ability to influence neurotransmission in the indirect striatonigral pathway, in particular by increasing the excitatory STN-SNr and STN-GP drives on the inhibitory nigrothalamic pathway, which results in a reduction of excitatory thalamocortical drive on the (motor) cortex (De Long, 1990; Amalric et al., 1994). The counteraction of the NT-induced increase in striatal and pallidal glutamate release by the NT receptor antagonist SR48692 suggests that NT receptor blockade in the striatum may be a novel and highly selective therapeutic approach, in combination with the "classical therapy," for the amelioration of extrapyramidal motor disorders such as Parkinson's disease. In addition, the fact that these NTinduced effects are observed at the nanomolar range strengthens the argument for a physiological role of this neuropeptide in modulating the motor function via the indirect strionigral pathway.

In conclusion, these results indicate that in addition to the well documented evidence for a presynaptic NT-dopamine interaction, striatal NT also operates postsynaptically to the dopamine afferents by increasing striatal GABA and glutamate, probably involving an activation of NT receptors located on striatal GABA cells projecting to the GP and a direct activation of NT receptors on the striatal glutamate terminals (Ferraro et al., 1995). The increase in pallidal GABA release probably reflects an activation of the striopallidal GABA pathway, whereas the increase in pallidal glutamate release reflects a disinhibition of the excitatory STN-GP pathway. These findings strengthen the evidence for a striatal NT receptor-mediated increase in GABA and glutamate transmission in the basal ganglia, which may contribute to the pathogenesis of some hypokinetic disorders (Sadoul et al., 1984; Fernandez et al., 1995). Thus, it may be suggested that striatal NT receptor blockade, in combination with classical antiParkinsonian drugs, could be helpful in ameliorating extrapyramidal hypokinetic motor disorders such as Parkinson's disease in which NT transmission may be pathologically increased because of a loss of inhibitory dopaminergic $\mathrm{D}_{2}$ tone on NT synthesis (Frey et al., 1986). 


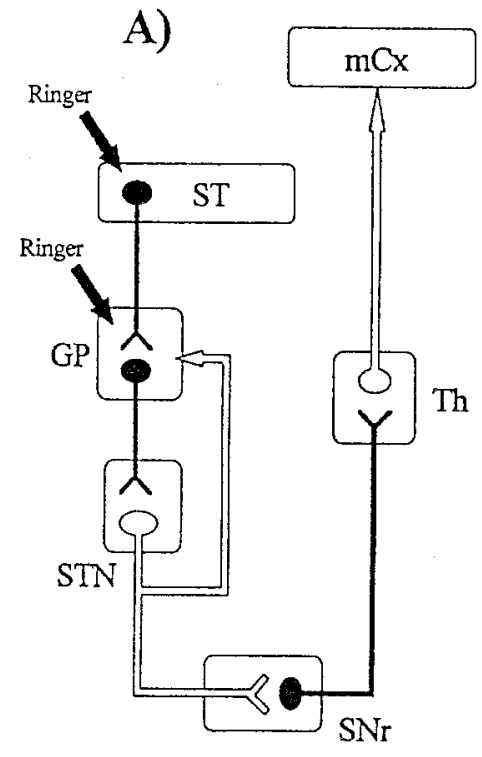

Control

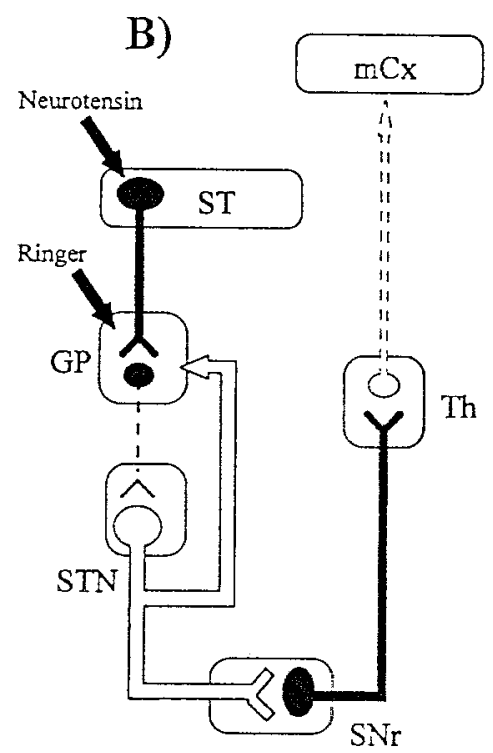

Neurotensin

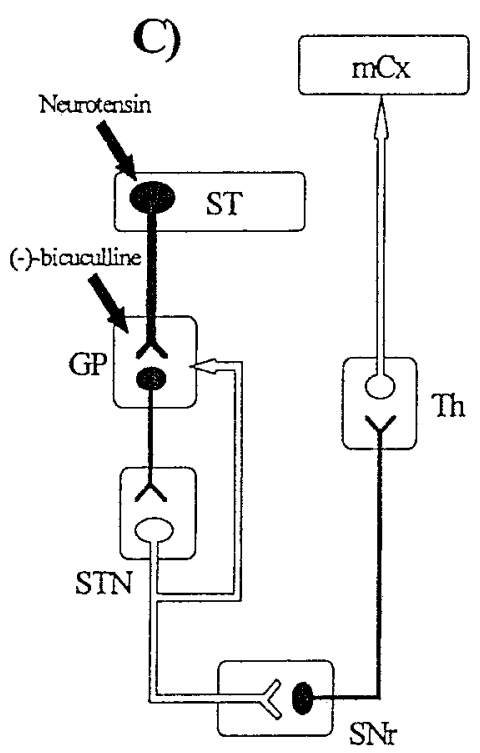

Neurotensin $+(-)$-bicuculline

Figure 10. Simplified schematic representation of the basal ganglia-thalamocortical neuronal circuitry indicating a possible mechanism underlying the NT-induced increase in striopallidal GABA release (and catalepsy). Inhibitory neurons (GABAergic) are shown as filled lines, and excitatory neurons (glutamatergic) are shown as open lines. GP, Globus pallidus; STN, subthalamic nucleus; $S N r$, substantia nigra pars reticulata; Th, thalamus; $m C x$, motor cortex. $A$, Untreated control. The striopallidal pathway forms one link in the indirect pathway that projects from the striatum to the basal ganglia output nuclei in the $\mathrm{SNr}$ and regulates the inhibitory nigral output to the thalamus. $B$, Intrastriatal NT. The increase in striatal and pallidal GABA release after intrastriatal NT reflects an activation of the striopallidal GABA transmission leading to a disinhibition of the excitatory STN-SNr and GP transmission. This effect increases the inhibitory drive of the nigrothalamic projections (as well as pallidal glutamate release), probably serving as a feedback to restore activity in the GABA pallidal-subthalamic pathway, thus reducing the activation of the indirect pathway and restoring motor activation. Intrastriatal NT administration has the net effect of decreasing excitatory thalamocortical transmission, resulting in catalepsy. $C$, Intrapallidal ( -$)$-bicuculline. Intrapallidal $\mathrm{GABA}_{\mathrm{A}}$ receptor blockade prevents the intrastriatal NT-induced increase in pallidal glutamate release.

\section{REFERENCES}

Agnati LF, Fuxe K, Benfenati F, Battistini N (1983) Neurotensin in vitro markedly reduces the affinity in subcortical limbic $\left[{ }^{3} \mathrm{H}\right] N$ propylnorapomorphine binding sites. Acta Physiol Scand 117:299-301.

Albin RL, Young AB, Penney JB (1989) The functional anatomy of basal ganglia disorders. Trends Neurosci 12:366-375.

Alexander GE, Crutcher M (1990) Functional architecture of basal ganglia circuits: neuronal substrates of parallel processing. Trends Neurosci 13:266-271.

Amalric M, Farin D, Dormont JF, Schmied A (1994) GABA-receptor activation in the globus pallidus and entopeduncolar nucleus: opposite effects on reaction time performance in the cat. Exp Brain Res 102:244-258.

Betancour C, Canton M, Gully D, Vela G, Pelaprat D, Rostene W (1995) Characterization and distribution of binding sites for a new neurotensin receptor antagonist ligand, $\left[{ }^{3} \mathrm{H}\right] \mathrm{SR} 48692$, in the guinea pig brain. J Pharmacol Exp Ther 273:1450-1458.

Blaha CD, Coury A, Fibiger HC, Phillips AG (1990) Effects of neurotensin on DA release and metabolism in the rat striatum and nucleus accumbens: cross-validation using in vivo voltammetry and microdialysis. Neuroscience 34:699-705.

Calò G, Sbrenna S, Bianchi C, Beani L (1997) Immediate and delayed effects of in vitro ischemia on glutamate efflux from guinea-pig cerebral cortex slices. Brain Res 751:300-306.

Carraway R, Leeman SE (1973) The isolation of a new hypotensive peptide, neurotensin, from bovine hypothalamus. J Biol Chem 248:6854-6861.

Castel MN, Morino P, Nylander I, Terenius L, HöKfelt T (1994) Differential dopaminergic regulation of the neurotensin striatonigral and striatopallidal pathways in the rat. Eur J Pharmacol 262:1-10.

Chevalier G, Deniau JM (1990) Disinhibition as a basic process in the expression of striatal functions. Trends Neurosci 13:277-280.

Da-Silva SL, Brandao ML, Tomaz C (1989) Behavioral effects of neurotensin applied to periventricular structures of rats. Braz J Med Biol Res 22:711-715.
Delfs JM, Anegawa NJ, Chesselet MF (1995) Glutamate decarboxylase messenger RNS in rat pallidum: comparison of the effects of haloperidol, clozapine, and combined haloperidol-scopolamine treatments. Neuroscience 66:67-80.

De Long MR (1990) Primate models of movement disorders of basal ganglia origin. Trends Neurosci 13:281-285.

Deutch AY, Zahm DS (1992) The current status of neurotensin-dopamine interactions: issues and speculations. Ann NY Acad Sci 668:232-252.

Drew KL, O’Connor WT, Kehr J, Ungerstedt U (1990) Regional specific effects of clozapine and haloperidol on GABA and dopamine release in rat basal ganglia. Eur J Pharmacol 187:385-397.

Fernandez A, Jenner P, Marsden CD, De Ceballos ML (1995) Characterization of neurotensin-like immunoreactivity in human basal ganglia: increased neurotensin levels in substantia nigra in Parkinson's disease. Peptides 16:339-346.

Ferraro L, Tanganelli S, O’Connor WT, Bianchi C, Ungerstedt U, Fuxe K (1995) Neurotensin increases endogenous glutamate release in the neostriatum of the awake rat. Synapse 20:362-364.

Ferraro L, O'Connor WT, Antonelli T, Fuxe K, Tanganelli S (1997) Differential effects of intrastriatal neurotensin(1-13) and neuroten$\sin (8-13)$ on striatal dopamine and pallidal GABA release. A dualprobe microdialysis study in the awake rat. Eur J Neurosci 9:1838-1846.

Frey P, Fuxe K, Eneroth P, Agnati LF (1986) Effects of acute and long-term treatment with neuroleptics on regional telecenphalic neurotensin levels in the male rat. Neurochem Int 8:429-434.

Fuxe K, von Euler G, Agnati LF, Merlo Pich E, O'Connor WT, Tanganelli S, Li XM, Tinner B, Cintra A, Carani C, Benfenati F (1992a) Intramembrane interactions between neurotensin receptors and dopamine $\mathrm{D}_{2}$ receptors as a major mechanism for the neuroleptic-like action of neurotensin. Ann NY Acad Sci 668:186-204.

Fuxe K, O'Connor WT, Antonelli T, Osborne PG, Tanganelli S, Agnati LF, Ungerstedt U (1992b) Evidence for a substrate of neuronal plasticity based on pre- and postsynaptic neurotensin-dopamine receptor interactions in the neostriatum. Proc Natl Acad Sci USA 89:5591-5595. 
Gerfen CR (1992) The neostriatal mosaic: multiple levels of compartmental organization. Trends Neurosci 15:133-139.

Gully D, Canton M, Boidegrain R, Jeanjean F, Molimard JC, Poncelet M, Gueudet C, Heaulme M, Leyris R, Brouard A, Pelaprat D, LabbeJullie C, Mazella J, Soubrié P, Maffrand JP, Rostene W, Kitbagi P, Le Fur G (1993) Biochemical and pharmacological profile of a potent and selective nonpeptide antagonist of the neurotensin receptor. Proc Natl Acad Sci USA 90:65-69.

Jennes L, Stumpf WE, Kalivas P (1982) Neurotensin: topographical distribution in rat brain by immunohistochemistry. J Comp Neurol 210:211-224.

Kehr J, Ungerstedt U (1989) Fast estimation of GABA in microdialysis perfusates: effects of nipecotic acid and 3-mercaptopropionic acid. J Neurochem 55:1309-1310.

Kita H (1992) Responses of globus pallidus neurons to cortical stimulation: intracellular study in the rat. Brain Res 589:84-90.

Masuo Y, Montagne MN, Pelaprat D, Scherman D, Rostene W (1990) Regulation of neurotensin-containing neurons in the rat striatum. Effects of unilateral striatal lesion with quinolinic acid and ibotenic acid on neurotensin content and its binding site density. Brain Res 520:6-13.

Nemeroff CB, Cain ST (1985) Neurotensin-dopamine interactions in the CNS. Trends Pharmacol Sci 6:201-205.

O'Connor WT, Tanganelli S, Ungerstedt U, Fuxe K (1992) The effects of neurotensin on GABA and acetylcholine release in the dorsal striatum of the rat: an in vivo microdialysis study. Brain Res 573:209-216.

Osborne PG, O'Connor WT, Beck O, Ungerstedt U (1994) Acute vs chronic haloperidol: relationship between tolerance to catalepsy and caudate and accumbens DA, GABA and acetylcholine release. Brain Res 643:20-30.

Parent A, Hazrati LN (1995) Functional anatomy of the basal ganglia. I. The cortico-basal ganglia-thalamo-cortical loop. Brain Res Rev 20:91-127.

Park MR, Falls WM, Kitai ST (1982) An intracellular HRP study of the rat globus pallidus. I. Responses and light microscopic analysis. J Comp Neurol 211:284-294.

Pasik P, Pasik T, Holstein GR (1987) Ultrastructural chemoanatomy of the basal ganglia: an overview. Adv Neurol 45:59-66.

Paxinos G, Watson C (1982) The rat brain in stereotaxic coordinates. New York: Academic.

Quirion R, Chiueh CC, Everist HD, Pert A (1985) Comparative localization of neurotensin receptors on nigrostriatal and mesolimbic dopaminergic terminals. Brain Res 327:385-389.
Quirion R, Rowe WB, Lapchak PA, Araujo DM, Beaudette A (1992) Distribution of neurotensin receptors in mammalian brain: what it is telling us about its interactions with other neurotransmitter systems. Ann NY Acad Sci 668:109-119.

Rosales MG, Martinez-Fong D, Morales R, Nunez A, Flores G, GongoraAlfaro JL, Floran B, Aceves J (1997) Reciprocal interactions between glutamate and dopamine in the pars reticulata of the rat substantia nigra: a microdialysis study. Neuroscience 80:803-810.

Sadoul JL, Chécler F, Kitabgi P, Rostène W, Javoy-Agid F, Vincent JP (1984) Loss of high affinity neurotensin receptors in substantia nigra from parkinsonian subjects. Biochem Biophys Res Commun 125:395-404.

Scheel-Kruger J (1986) Dopamine GABA interactions: evidence the GABA transmits, modulates and mediates dopaminergic function in the basal ganglia and the limbic system. Acta Neurol Scand 73:9-54.

Shandra OA, Hodlevskyi LS, Panenko AV, Vastianov RS, Oliinyk AA (1994) Effect of intracerebral administration of somatostatin and neurotensin on posture and movement disorders. Fiziol $\mathrm{Zh}$ 40:71-77.

Shibata K, Yamada K, Furukawa T (1987) Possible neuronal mechanisms involved in neurotensin-induced catalepsy in mice. Psychopharmacology 91:288-292.

Sirinathsinghji DJS, Heavens RP (1989) Stimulation of GABA release from the rat neostriatum and globus pallidus in vivo by corticotropinreleasing factor. Neurosci Lett 100:203-209.

Soltis RP, Anderson LA, Walters JR, Kelland MD (1994) A role for non-NMDA excitatory amino acid receptors in regulating the basal activity of rat globus pallidus neurons and their activation by the subthalamic nucleus. Brain Res 666:21-30.

Steinberg R, Rodier D, Mons G, Gully D, Le Fur G, Soubrié P (1995) SR48692-sensitive neurotensin receptors modulate acetylcholine release in rat striatum. Neuropeptides 29:27-31.

Tanganelli S, O'Connor WT, Ferraro L, Bianchi C, Beani L, Ungerstedt U, Fuxe K (1994) Facilitation of GABA release by neurotensin is associated with a reduction of dopamine release in rat nucleus accumbens. Neuroscience 60:649-657.

von Euler G, Fuxe K (1987) Neurotensin reduces the affinity of $\mathrm{D}_{2}$ receptors in rat striatal membranes. Acta Physiol Scand 131:625-626.

Wagstaff JD, Gibb JW, Hanson GR (1996) Dopamine $\mathrm{D}_{2}$-receptors regulate neurotensin release from nucleus accumbens and striatum as measured by in vivo microdialysis. Brain Res 721:196-203. 